\title{
Jean-Charles Monferran, Horace dans les "CEuvres poetiques" de Jacques Peletier du Mans (1547)
}

\section{Filippo Fassina}

\section{(2) OpenEdition}

1 Journals

\section{Edizione digitale}

URL: http://journals.openedition.org/studifrancesi/9823

DOI: 10.4000/studifrancesi.9823

ISSN: 2421-5856

\section{Editore}

Rosenberg \& Sellier

\section{Edizione cartacea}

Data di pubblicazione: 1 octobre 2007

Paginazione: 426

ISSN: 0039-2944

\section{Notizia bibliografica digitale}

Filippo Fassina, "Jean-Charles Monferran, Horace dans les "CFuvres poetiques" de Jacques Peletier du Mans (1547)», Studi Francesi [Online], 152 (LI | II) | 2007, online dal 30 novembre 2015, consultato il 09 janvier 2021. URL: http://journals.openedition.org/studifrancesi/9823 ; DOI: https://doi.org/10.4000/ studifrancesi.9823

Questo documento è stato generato automaticamente il 9 janvier 2021.

\section{(c)}

Studi Francesi è distribuita con Licenza Creative Commons Attribuzione - Non commerciale - Non opere derivate 4.0 Internazionale. 


\section{Jean-Charles Monferran, Horace dans les "CEuvres poetiques" de Jacques Peletier du Mans (1547)}

Filippo Fassina 


\section{NOTIZIA}

JEAN-CHARLES MONFERRAN, Horace dans les “CEuvres poetiques” de Jacques Peletier du Mans

(1547), «Bibliothèque d'Humanisme et Renaissance», LXVIII, 3 (2006), pp. 517-533.

Il presente lavoro è incentrato sull'analisi delle CEuvres poétiques di Jacques Peletier du Mans (1547), definite da Monferran «une étape essentielle dans l'histoire de la réception d'Horace $a u \mathrm{XVI}^{\mathrm{e}}$ siècle». L'autore analizza la struttura dell'opera (bipartita in traduzioni dei Carmina di Orazio e testi personali di Peletier du Mans) che segna un percorso dalla Grecia antica fino a Petrarca e alla Francia e sottolinea il debito nei confronti dell'Adolescence clémentine di Marot. Il ruolo di Orazio in quest'opera è quello di trait d'union tra la parte dedicata alla traduzione e i «vers lyriques» composti da Peletier: la varietas metrica è ripresa infatti sia nelle traduzioni sia nei componimenti originali. Anche dal punto di vista tematico ed etico le analogie sono messe in evidenza da Monferran: centrale è il topos della mediocritas e dell'otium agreste, ripreso anche nella traduzione di Marziale. L'autore sottolinea però la sostanziale autonomia di Peletier da Orazio, evidente soprattutto nei «vers lyriques», in cui il modello oraziano offre solo il soggetto, ma, per il resto, risulta abbastanza lontano. In conclusione Monferran ribadisce l'importanza di questa raccolta che rappresenta un'innovazione nel mondo della traduzione-reinterpretazione, ma un'innovazione che agisce «discrètement» e forse proprio per questo motivo le CEuvres poétiques di Peletier du Mans non hanno meritato l'attenzione degli studiosi riservata invece alle opere di Du Bellay o di Ronsard. 